\title{
Self-reported cognitive symptoms following mild traumatic brain injury are poorly associated with neuropsychological performance in OIF/OEF veterans
}

\author{
Robert J. Spencer, PhD; ${ }^{1}$ Lauren L. Drag, PhD; ${ }^{2}$ Sara J. Walker, PhD; ${ }^{1}$ Linas A. Bieliauskas, PhD $^{1-2 *}$ \\ ${ }^{1}$ Department of Mental Health Services, Department of Veterans Affairs Ann Arbor Healthcare System, Ann Arbor, MI; \\ ${ }^{2}$ Department of Psychiatry, University of Michigan Health System, Ann Arbor, MI
}

\begin{abstract}
Mild traumatic brain injury (mTBI) is not uncommon among Operation Iraqi Freedom/Operation Enduring Freedom (OIF/OEF) veterans, and many individuals within this group report lingering cognitive difficulties following their injury. For Department of Veterans Affairs clinicians, an accurate assessment of cognitive symptoms is important in providing appropriate clinical care. Although self-assessment is commonly employed to screen for difficulties in cognitive functioning, little is known about the accuracy of self-report in this population. This study collected cognitive, psychiatric, and self-report data from 105 OIF/OEF veterans with mTBI to examine the relationship between self-reported cognitive functioning and objective neuropsychological test performance. Additionally, clinicians who frequently work with OIF/OEF veterans were asked to predict the magnitude of these associations. Self-reported cognitive functioning was not significantly correlated with objective cognitive abilities, suggesting that objective neuropsychological testing should be used when cognitive weakness is suspected. Perceived cognitive deficits were associated with depression, anxiety, and posttraumatic stress disorder, illustrating the additional importance of adequate assessment and treatment of psychiatric symptoms. Clinicians tended to overestimate the association between selfreport and test performance.
\end{abstract}

Key words: anxiety, brain injury, cognition, depression, insight, military, neuropsychological assessment, self-report, traumatic psychometrics, veterans.

\section{INTRODUCTION}

By some estimates, 15 to 20 percent of Operation Iraqi Freedom/Operation Enduring Freedom (OIF/OEF) veterans meet criteria for mild traumatic brain injury (mTBI) [1-3], although some authors have argued that such estimates are inflated because of overly inclusive diagnostic criteria [4]. The American Congress of Rehabilitation Medicine defines mTBI as a head trauma that produces (1) a loss of consciousness of 30 minutes or less, (2) any loss of memory immediately before or after the accident, (3) any alteration in mental state at the time of the accident, or (4) focal neurological deficit(s) [5]. Additional criteria include posttraumatic amnesia of less than 24 hours and a Glasgow Coma Scale score of 13 or higher 30 minutes postinjury. Among the majority of

Abbreviations: $\mathrm{mTBI}=$ mild traumatic brain injury, $\mathrm{OIF} / \mathrm{OEF}=$ Operation Iraqi Freedom/Operation Enduring Freedom, PTSD = posttraumatic stress disorder, RBANS = Repeatable Battery for the Assessment of Neuropsychological Status, RCFT = Rey Complex Figure Test, $\mathrm{SD}=$ standard deviation, $\mathrm{TBI}=$ traumatic brain injury, VA = Department of Veterans Affairs.

*Address all correspondence to Linas A. Bieliauskas, PhD; 2101 Commonwealth Blvd, Suite C, Ann Arbor, MI 48105; 734-936-6619; fax: 734-936-9262. Email: linas@umich.edu DOI:10.1682/JRRD.2009.11.0181 
individuals with mTBI, most of the resultant symptoms tend to remit [6-7]. Although the expectation is that mTBI sequelae are transient for most people, some individuals nevertheless continue to report persistent cognitive problems, leaving clinicians with the task of assessing the clinical characteristics and possible etiology of some of these symptoms to provide adequate clinical care.

Clinicians at Department of Veterans Affairs (VA) medical centers face unique challenges when assessing cognitive effects of mTBI in combat veterans, because combat-related injuries are complicated by multiple factors, many of which can also affect cognitive functioning. Soldiers with mTBI may experience emotional and other physical trauma at the time of the injury, have cumulative effects of multiple injuries sustained over a tour of duty, or have a high incidence of comorbid mental health conditions, especially posttraumatic stress [2,8-9]. Further complicating the clinical picture, assessment of postinjury symptoms typically relies heavily on self-report of symptoms. In addition, the cognitive and physical complaints associated with history of mTBI are not specific to head injury; many are also common to psychiatric or other medical disorders [10-14]. For example, according to the Diagnostic and Statistical Manual of Mental Disorders-Fourth Edition, postconcussional disorder can include symptoms such as fatigue, anxiety or depression, apathy, irritability, and disordered sleep [15]. These symptoms overlap significantly with those found in depression, anxiety, and posttraumatic stress disorder (PTSD), disorders common among returning veterans. In addition, these comorbid symptoms, such as chronic pain, depression, and posttraumatic stress, can impair cognitive functioning independently of the aftereffects of head injury [16].

The overlapping symptoms of mTBI and co-occurring conditions leave VA clinicians with the difficult task of determining the degree to which cognitive problems exist independently of other psychiatric and physical comorbidities (e.g., Vasterling et al. [17]). Assessment of patients with suspected mTBI can involve a number of subjective and objective methods, including neuroimaging, neuropsychological testing, and clinical assessment including patient self-report. Although neuropsychological evaluation can provide objective quantification of cognitive abilities, these assessments are time- and resource-intensive on the part of both the VA and the veteran and it is typically not plausible to refer every veteran with suspected mTBI for full evaluation. Because of this limitation, self-report is often used for screening for cognitive dysfunction and may be the sole source of information available to the clinician when making treatment and referral decisions. Although self-report of cognitive impairments offers the clinician insight into the perceived day-to-day functioning of the individual, the validity of these reports has been questioned in multiple populations on the basis of poor correlations with performance on neuropsychological testing. Self-report of cognitive abilities has been shown to correlate poorly with neuropsychological performance in individuals with multiple sclerosis [18], mild to moderate head injury [19], human immunodeficiency virus [20], and bipolar disorder [21], as well as in nonclinical populations [22-23].

Given the recent influx of returning OIF/OEF veterans seeking treatment at VA medical centers for subjective cognitive complaints following possible head injury, the importance of efficiently assessing cognitive functioning in this population has become increasingly salient. A better understanding of the relationship between self-reported cognitive impairment and objective neuropsychological performance can aid clinicians in making assessment, referral, and treatment decisions. To our knowledge, only one study has examined the accuracy of self-reported cognitive functioning in a VA population [24]. Gass and Apple examined individuals with a history of mild to severe closed head injury and found that self-report of cognitive function was strongly related to emotional distress but related to only select neuropsychological tasks [24]. The current study builds on their findings by examining the association between self-reported cognitive functioning and performance among a sample of OIF/OEF veterans.

Given that self-report is often the only measure of cognitive functioning available to clinicians when making treatment decisions, it is also important to understand clinicians' perceptions regarding the accuracy of this information. In the current study, clinicians with direct involvement in the clinical care of OIF/OEF veterans were asked to estimate the overall correlation between self-reported cognitive symptoms and actual test performances among these patients. Comparing clinicians' estimations with the actual correlations between self-reports and test results should help determine whether clinicians accurately perceive patients' insight into their cognitive abilities. 


\section{METHODS}

\section{Study One: Relationship Between Testing and Self- Report}

\section{Participants}

This study examined data from 105 veterans, all of whom screened positive for possible head injury on a standard VA clinical reminder consisting of postconcussive symptoms, which is given to all returning OIF/OEF veterans. The veterans in this study were consecutive referrals seen in the Traumatic Brain Injury (TBI) Clinic at the VA Ann Arbor Healthcare System for a more comprehensive medical examination, part of which included a brief neuropsychological assessment. Veterans were excluded from the current study if they were seen as part of a compensation and pension evaluation or if they demonstrated evidence of inconsistent effort on neuropsychological testing, as indicated by a score of eight or below on the Rey 15-item Memory Test. Veterans exceeding criteria for mTBI (e.g., loss of consciousness greater than 30 minutes or posttraumatic amnesia greater than 24 hours) were also excluded. A total of 17 veterans were undergoing a compensation and pension examination, 12 had sustained a moderate or severe TBI, and 4 had poor effort during testing. After accounting for overlapping exclusion criteria, we excluded 29 veterans, leaving a total sample of 105 . Veterans ranged in age from 21 to 58 (mean \pm standard deviation [SD] $=29.8 \pm$ 8.2) and had education levels ranging from 7 to 18 years (mean $\pm \mathrm{SD}=12.9 \pm 1.4$ ). Of the 105 veterans, 58 percent reported no loss of consciousness. Among those individuals reporting a loss of consciousness, the mean duration was 7.4 minutes $(\mathrm{SD}=8.3$ ) with a range of less than 1 minute to 30 minutes. A period of disorientation lasting 30 minutes or less was reported by 71 percent of veterans (median $=15.0$ ), and posttraumatic amnesia lasting 30 minutes or less was reported by 94 percent of veterans.

\section{Materials and Procedures}

All veterans screened positive during a clinical reminder for TBI. Veterans completed self-report checklists, underwent a physical and psychosocial examination by a physician, and completed neuropsychological testing.

\section{Neuropsychological Assessment}

Self-report ratings of cognitive functioning were obtained from the veteran's responses on the 22-item
VA-standardized checklist given to all returning OIF/ OEF veterans as part of their comprehensive evaluation for TBI. As part of this screen, veterans provided subjective ratings in three domains: concentration, memory, and thinking/organization (see Appendix 1, available online only, for item content). Veterans rated their cognitive abilities within each of these three domains on a scale from 0 to 4; a 0 indicated no problem at all and a 4 indicated that the problem is almost always present and the veteran has been unable to perform at work, school, or home because of the problem.

Veterans also completed a 45-minute neuropsychological examination as part of standard clinical care in the TBI Clinic. This examination assessed aspects of attention and concentration, memory, and executive functioning, as well as psychiatric symptoms. Selfreported symptoms of anxiety and depression were collected with use of the Hospital Anxiety and Depression Scale [25]. Symptoms of PTSD were measured with use of the PTSD Checklist-Military Version [26]. Cognitive measures included parts A and B of the Trail Making Test [27], the Story Memory subtest from the Repeatable Battery for the Assessment of Neuropsychological Status (RBANS) [28], the Rey Complex Figure Test (RCFT) [29], the Digit Span subtest of the Wechsler Adult Intelligence Scale-IV [30], and the vocabulary section from the Shipley Institute of Living Scale [31]. Some veterans were not administered all tasks, and thus, the number of veterans completing each measure ranged from 87 to 105.

Neuropsychological measures were categorized into three nonexclusive domains to match the domains assessed on the 22-item screen: concentration, memory, and thinking/organization. The domains were nonexclusive so that tests measuring multiple abilities could be compared with self-reports of those same abilities. Measures of attention included scores on the forward, backward, and sequencing components of the Digit Span task and the time to completion on Trails A and Trails B. Measures of memory were the immediate and delayed story recall from the RBANS and immediate recall from the RCFT. Measures of thinking/organization included the backward and sequencing subtests of the Digit Span; time to completion on Trails A and Trails B; and copy accuracy, time to copy, and copy organization [32] from the copy trial of the RCFT. With the exception of copy organization from the RCFT, raw scores were converted to standard scores based on age-referenced norms in 
order to eliminate age effects and allow for normative comparisons. Impairment on each task was determined by a standard score of 2 or more SD below the normative mean. This threshold for impairment was set because it is traditionally a conservative threshold for determining an impairment in neuropsychological screening. Because age norms were not available for the organization score from the RCFT copy trial, a raw score of zero or one out of six was classified as impaired [33-34].

\section{Study Two: Clinician Survey}

\section{Participants}

A sample of 41 clinicians completed an anonymous survey pertaining to the relationship between self-reported cognitive functioning and objective neuropsychological test performance. These individuals were healthcare providers at the VA Ann Arbor Healthcare System and/or the University of Michigan and included 12 physicians (29\%), 9 nurses (22\%), 8 physical therapists (20\%) 4 social workers (10\%), and 8 others (pharmacists, psychologists, occupational therapists, and a nutritionist; 20\%). Of these 41 clinicians, 22 reported that they regularly refer patients for neuropsychological testing.

\section{Materials and Procedures}

Clinicians completed a survey in which they were asked to estimate the correlation between self-reported cognitive impairment and performance on neuropsychological testing among OIF/OEF veterans undergoing assessments for suspected TBI. This sample constituted a convenience sample, in that the clinicians were approached in the hospital by the first author and asked to participate in the study. They were informed that participation was anonymous, and they were provided with an interdepartmental envelope in which to place surveys. No clinician refused participation in person, but how many simply declined to return the envelope to the interdepartmental mail is unknown. Clinicians estimated correlations in three domains: memory, concentration, and thinking/organization. The survey is presented in Appendix 2 (available online only).

\section{RESULTS}

\section{Study One: Relationship Between Testing and Self- Report}

Given the ordinal nature of the self-report data examined in this study, Spearman rho correlations were used to examine the relation between self-report ratings and the individual test performance within each domain. Spearman rho correlations were also used to examine the relationship between self-report ratings and measures of depression, anxiety, and PTSD. Results are displayed in Table 1. Self-report ratings of attention and thinking/ organization were not significantly associated with cognitive performance on any of the neuropsychological measures within the respective domains. Within the memory domain, self-reported memory impairment was significantly associated with RBANS delayed story recall $(r=-0.20, p=0.04)$. However, self-reported memory impairment was not significantly associated with RBANS immediate story recall or RCFT immediate recall. To account for possible effects of premorbid functioning, we reran these analyses using partial correlations with an estimate of premorbid intelligence (as measured by age-normed performance on the Shipley Vocabulary subtest) included as a control variable. These results were unchanged from our previous findings.

Scores on measures of depression, anxiety, and PTSD were significantly correlated to self-report ratings in all three domains (all correlations $p<0.001$ ), as shown in Table 1. Positive correlations indicated that a higher number of psychiatric symptoms was associated with a higher degree of subjective cognitive impairment. A post hoc multivariate linear regression was used to examine whether psychiatric symptoms mediated the relationship between self-reported memory and RBANS delayed story recall. Depression, anxiety, PTSD, and self-reported memory impairment were entered as predictors into the regression equation, with RBANS delayed story recall as the dependent variable. Anxiety was the only significant predictor variable $(\beta=-0.29, p=0.05)$ in this model, and self-reported memory impairment was no longer associated with RBANS delayed story recall ( $\beta=0.003$, not significant).

Tables 2 through 4 show the frequency of self-report ratings as a function of performance on the tests within each of the three domains. Within each domain, the percentage of veterans who scored in the "impaired" range (i.e., 2 or more SD below age-referenced normative data) on one or more tests ranged from 9 to 41 percent. In contrast, the percentage of veterans endorsing some degree of cognitive difficulty in each domain ranged from 88 to 94 percent. Within the attention domain, 93 of 102 veterans (91\%) performed within normal limits on all five attention tests; however only 6 of these 93 veterans (6\%) 
Table 1.

Correlations between OIF/OEF veterans' self-reported cognitive problems and performance on neuropsychological tests of corresponding functions.

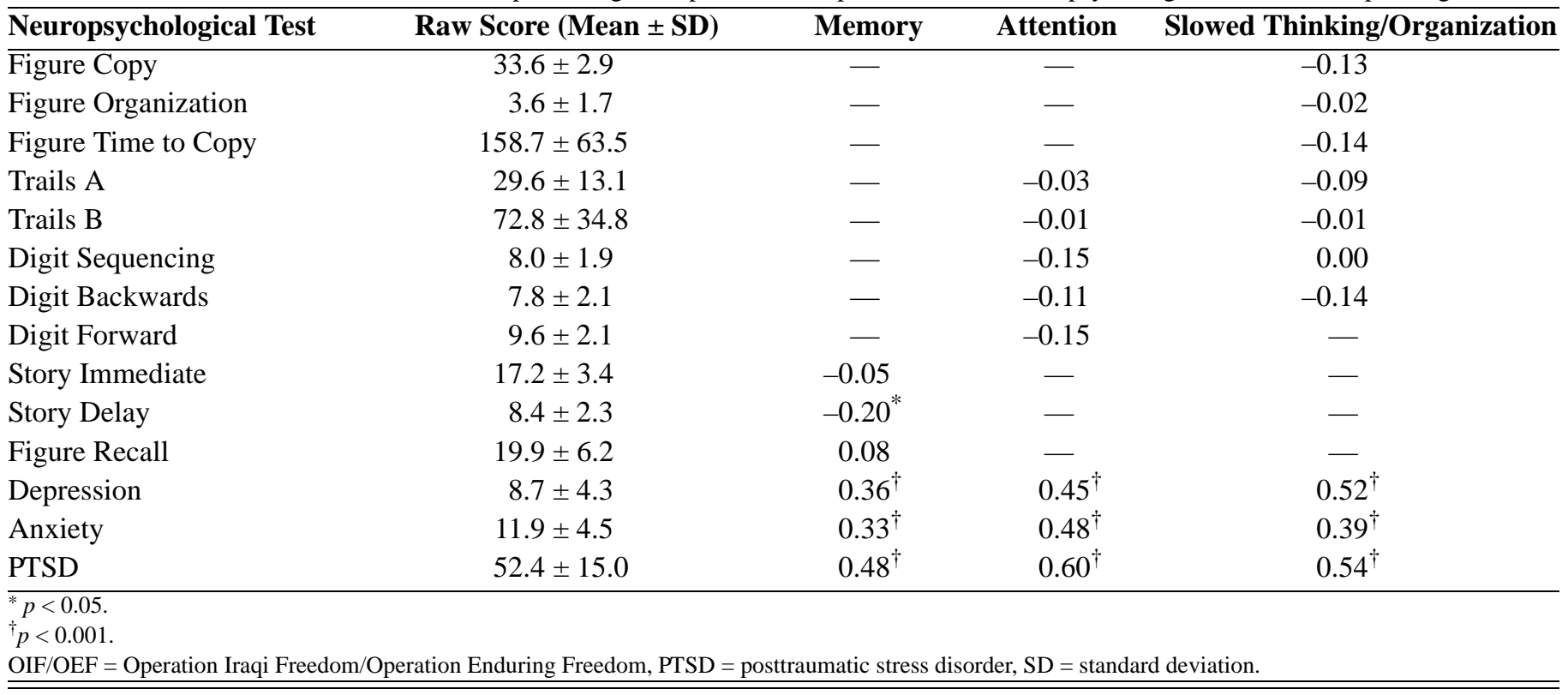

Table 2.

Number of impaired memory tests at each level of patient self-rated memory problems.

\begin{tabular}{lcccc}
\hline Self-Rating & No Impaired Scores & 1 Impaired Score & 2-3 Impaired Scores & Total \\
\hline Not At All & 6 & 1 & 0 & 7 \\
Mild & 6 & 3 & 0 & 9 \\
Moderate & 25 & 9 & 4 & 38 \\
Severe & 13 & 5 & 4 & 22 \\
Very Severe & 19 & 7 & 1 & 27 \\
Total & 69 & 25 & 9 & 103 \\
\hline Note: Score was deemed "impaired" if performance fell <2 standard deviations below age-adjusted mean performance. & \\
\hline
\end{tabular}

Table 3.

Number of impaired attention and concentration tests at each level of patient self-rated attention and concentration problems.

\begin{tabular}{lccrr}
\hline Self-Rating & No Impaired Scores & 1 Impaired Score & 2-5 Impaired Scores & Total \\
\hline Not At All & 6 & 0 & 0 & 6 \\
Mild & 16 & 1 & 0 & 17 \\
Moderate & 29 & 1 & 2 & 32 \\
Severe & 24 & 1 & 3 & 28 \\
Very Severe & 18 & 0 & 1 & 19 \\
Total & 93 & 3 & 6 & 102 \\
\hline
\end{tabular}

Note: Score was deemed "impaired" if performance fell <2 standard deviations below age-adjusted mean performance.

who performed within the normal range reported intact attentional abilities. Within the memory domain, 69 of 103 veterans $(67 \%)$ performed within normal limits on all three memory tasks but only 6 of these $69(9 \%)$ who performed within the normal range reported normal memory abilities. Performance was within normal limits on all seven measures of processing speed or organization for 75 of 103 veterans (73\%), and only 8 (10\%) of these individuals who performed within the normal range reported intact functioning. 
JRRD, Volume 47, Number 6, 2010

Table 4.

Number of slowed information processing or organization tests at each level of patient self-rated slowed information processing or organizational problems.

\begin{tabular}{lcccr}
\hline Self-Rating & No Impaired Scores & 1 Impaired Score & 2-7 Impaired Scores & Total \\
\hline Not At All & 8 & 4 & 0 & 12 \\
Mild & 16 & 3 & 1 & 20 \\
Moderate & 23 & 7 & 5 & 35 \\
Severe & 12 & 2 & 2 & 16 \\
Very Severe & 16 & 3 & 1 & 20 \\
Total & 75 & 19 & 9 & 103 \\
\hline
\end{tabular}

Note: Score was deemed “impaired” if performance fell $<2$ standard deviations below age-adjusted mean performance.

\section{Study Two: Clinician Survey}

Clinician-estimated correlations between self-report and neuropsychological performance in the memory domain ranged from 0.30 to 1.00 (mean $\pm \mathrm{SD}=0.67 \pm$ 0.16). Clinician estimates ranged from 0 to 1.00 (mean \pm $\mathrm{SD}=0.60 \pm 0.24$ ) in the attention domain and from 0 to 0.90 in the thinking/organization domain (mean $\pm \mathrm{SD}=$ $0.61 \pm 0.24)$.

\section{DISCUSSION}

Results from this study indicate that, in general, selfreport ratings of cognitive impairment are not significantly correlated with objective neuropsychological testing in a sample of OIF/OEF veterans undergoing TBI evaluation. Self-report ratings were, however, significantly correlated with symptoms of anxiety, depression, and PTSD such that higher psychiatric symptoms were associated with higher ratings of cognitive impairment. The only significant finding with respect to self-report and cognition was between self-reported memory impairment and RBANS delayed story recall. However, post hoc regression analyses demonstrated that anxiety was a significant mediating variable and that the relationship between self-reported memory and delayed story recall was no longer significant upon controlling for anxiety. These findings suggest that self-assessment of cognitive impairment is not a valid indicator of true cognitive functioning as measured by objective assessment. Nevertheless, perceived cognitive abilities were associated with psychiatric symptoms. This is consistent with previous findings by Chamelian and Feinstein, who concluded that among a sample of civilians with mild to moderate head injury, subjective cognitive complaints were significantly associated with depressive symptoms [35].
One reason for the lack of correspondence between self-reported cognitive functioning and test performance may be that many patients have a biased recollection of premorbid functioning. Individuals typically overestimate their level of preinjury functioning [36], which can lead to inflated estimates of impairment. In addition, perception of current cognitive functioning can be affected by comorbid factors like depression; depressed individuals tend to take a globally negative self-view, leading to overly negative reports of cognitive functioning [37-38].

In the current study, medical professionals tended to overestimate the correlation between self-report and test performance, suggesting that clinicians may tend to overestimate the accuracy of self-reported symptoms. The clinicians in this study predicted a rather strong relationship between self-report and objective testing, possibly assuming that one source of information can be an acceptable substitute for the other. While self-report can provide important insight into individuals' perception of their functional abilities, clinicians should also become more aware of its limitations. Utilizing neuropsychological tests can provide additional objective information that cannot be gleaned by self-report alone. Our findings suggest that there is merit in using even brief (i.e., 45-minute) neuropsychological screening as an adjunct to self-report so that clinicians can make more informed treatment decisions in order to most efficiently allocate resources to veterans. We found that many veterans who reported cognitive impairment performed within normal limits on objective testing, suggesting that a brief and efficient neuropsychological battery may sufficiently rule out cognitive dysfunction in many cases.

\section{Depression, Anxiety, and Posttraumatic Stress Disorder}

Significant correlations between perceived cognitive impairment and anxiety, depression, and PTSD illustrate the importance of identifying and treating comorbid 
psychiatric symptoms. In our sample, 87 percent of veterans presenting with mTBI symptoms also endorsed significant symptoms of depression, anxiety, and/or PTSD based on clinical cutoffs, which is consistent with previous estimates [9]. Depression, anxiety, and PTSD can lead to negative self-concept, a low sense of self-efficacy, self-criticism, and a tendency to catastrophize [3942], any of which can affect self-assessment and lead to self-report biases. Thus, clinicians should thoroughly assess and consider psychiatric symptoms when evaluating cognitive complaints. Adequate treatment of these symptoms may contribute to improved cognitive functioning.

\section{Relationships Between Self-Report and Test Performance}

Various results yielded from even a brief neuropsychological screen can have important implications for clinical decision-making. A noteworthy finding from the current study is that veterans who did not report cognitive impairment typically did not demonstrate evidence of cognitive dysfunction on the neuropsychological tests. Impairment rates in this group actually resembled the normal variation in abilities that would be expected in a healthy nonclinical sample. This finding suggests that neuropsychological screening may not be necessary for veterans who report no cognitive difficulties and that clinicians can be more confident about the accuracy of selfreport in such cases.

The more common finding in this study was that veterans reported cognitive impairments of at least moderate severity but performed within normal limits on neuropsychological testing. These individuals may have valid, if non-neurological-related, reasons for their perceived cognitive difficulties, such as the psychiatric symptoms previously discussed. Also possible is that the evaluation setting is not reflective of the veterans' daily environment, in which multiple demands, distractions, and psychosocial stressors can affect functioning. Nevertheless, veterans who perform within normal limits will benefit from assurances that their cognitive abilities are intact and from learning ways to optimize these abilities in their daily environment. Such veterans may benefit from assistance with emotional readjustment to civilian life and/or treatment of psychiatric symptoms. A small subset of individuals did demonstrate significant cognitive impairment on the neuropsychological screen. These individuals would benefit from referrals for more comprehensive neuropsychological evaluations in which factors such as effort, emotional functioning, and component cognitive abilities can be addressed in detail. Neuropsychologists are trained to assess and integrate biological, social, and psychological data in clinical work. Given the biopsychosocial complexity of most patients returning from service in OIF/OEF, this outlook is well suited to TBI evaluations within the VA [6].

\section{Limitations and Future Directions}

One limitation to the current study is that self-report was assessed with use of a standardized 4-item screen. Although this screen is part of a VA-wide screening instrument, it does not allow for the more detailed and openended questioning that can be used in face-to-face contact with patients. An unstructured interview by a clinician is likely to yield more information than this 4-question screen. However, the accuracy of this additional information is also unknown and should be examined with future research. Another limitation is the potential ambiguity of the screening questions. Veterans may interpret the questions as assessing the worst extent of previous symptoms (regardless of current functioning), the average level of problems caused by the symptoms, and/or the current impact of the symptoms on daily functioning. Different interpretations of the questions may lead to variable and possibly inaccurate self-report responses.

The current study did not use measures of baseline cognitive functioning when examining current cognitive performance. However, veterans made self-report ratings of perceived disruptions in functional abilities rather than perceived changes in abilities. Cognitive difficulties significant enough to lead to functional impairments should lead to observable deficits on norm-referenced neuropsychological testing, independent of the veteran's level of premorbid functioning (e.g., average cognitive functioning for someone with above-average premorbid abilities should not lead to a disruption in his or her ability to carry out daily activities). Other directions for future research include examining the role of brief neuropsychological testing in the context of mTBI to assess its contributions to clinical care and treatment planning beyond the usual assessment methods. Evaluating the accuracy of self-reported cognitive functioning among veterans with moderate and/or severe combat-related head injuries would also contribute to this area of research.

Only a small proportion of the veterans in the current study failed effort testing, yet many of these individuals performed more poorly on testing than one might expect among an unimpaired sample. Although mTBI might 
appear to produce significant cognitive symptoms, an alternative explanation is that the effort test used, the Rey 15-Item Memory Test, is less sensitive to poor effort in this relatively healthy sample. The complications of potential secondary gain (such as compensation for combatrelated symptoms) in forming perception of symptoms were not addressed in this study and bear further investigation. The current study did not include individuals undergoing compensation and pension evaluations. Because these individuals have an obvious motivation to overreport problems, a replication of the current study among these individuals is needed.

Finally, the observed lack of correspondence between self-reported cognitive symptoms and objective measures (i.e., neuropsychological testing) could be extended toward examining the relationship between these sources of data and data from other technologies, such as neuroimaging. Although the current results seem to suggest that self-report is inadequate, several alternative possibilities exist, including that testing is insensitive to mTBI impairments, that self-reports are inadequate, or that both sources of information can be efficiently used in conjunction with one another in some fashion.

\section{CONCLUSIONS}

Self-reported cognitive functioning is significantly related to psychiatric symptoms and is poorly associated with objective neuropsychological test performance. The lack of correspondence was greatly underestimated by the medical professionals in this study. Clinicians should appreciate this limitation and use neuropsychological testing whenever assessment of cognitive abilities is needed.

\section{ACKNOWLEDGMENTS}

\author{
Author Contributions: \\ Study concept and design: R. J. Spencer, S. J. Walker, L. L. Drag, \\ L. A. Bieliauskas. \\ Acquisition of data: R. J. Spencer, S. J. Walker. \\ Analysis and interpretation of data: L. L. Drag, R. J. Spencer, \\ S. J. Walker, L. A. Bieliauskas. \\ Drafting of manuscript: R. J. Spencer, L. L. Drag, S. J. Walker. \\ Critical revision of manuscript for important intellectual content: \\ R. J. Spencer. \\ Statistical analysis: L. L. Drag, R. J. Spencer. \\ Administrative, technical, or material support: L. A. Bieliauskas.
}

Study supervision: L. A. Bieliauskas, R. J. Spencer.

Financial Disclosures: The authors have declared that no competing interests exist.

Funding/Support: This material was unfunded at the time of manuscript preparation.

Additional Contributions: We would like to thank Lisa A. DiPonio, MD, and Percival H. Pangilinan, MD, for their assistance in data collection. We would also like to thank the reviewers of an earlier draft of this manuscript for their helpful comments.

Institutional Review: The Institutional Review Board at the Ann Arbor VA Healthcare Center approved this study and granted a waiver of consent.

Participant Follow-Up: The authors do not plan to inform participants of the publication of this study.

\section{REFERENCES}

1. Belanger HG, Uomoto JM, Vanderploeg RD. The Veterans Health Administration's (VHA's) Polytrauma System of Care for mild traumatic brain injury: Costs, benefits, and controversies. J Head Trauma Rehabil. 2009;24(1):4-13. [PMID: 19158591] DOI:10.1097/HTR.0b013e3181957032

2. Hoge CW, McGurk D, Thomas JL, Cox AL, Engel CC, Castro CA. Mild traumatic brain injury in U.S. Soldiers returning from Iraq. N Engl J Med. 2008;358(5):453-63. [PMID: 18234750] DOI:10.1056/NEJMoa072972

3. Tanielian TL, Jaycox L; RAND Corporation. Invisible wounds of war: Psychological and cognitive injuries, their consequences, and services to assist recovery. Santa Monica (CA): RAND; 2008.

4. Hoge CW, Goldberg HM, Castro CA. Care of war veterans with mild traumatic brain injury-Flawed perspectives. N Engl J Med. 2009;360(16):1588-91. [PMID: 19369664] DOI:10.1056/NEJMp0810606

5. Kay T, Harrington DE, Adams R. Definition of mild traumatic brain injury. J Head Trauma Rehabil. 1993;8:86-87. DOI:10.1097/00001199-199309000-00010

6. McCrea MA; American Academy of Clinical Neuropsychology. Mild traumatic brain injury and postconcussion syndrome: The new evidence base for diagnosis and treatment. New York (NY): Oxford University Press; 2008.

7. Schretlen DJ, Shapiro AM. A quantitative review of the effects of traumatic brain injury on cognitive functioning. Int Rev Psychiatry. 2003;15(4):341-49. [PMID: 15276955] DOI:10.1080/09540260310001606728

8. Lew HL, Poole JH, Vanderploeg RD, Goodrich GL, Dekelboum S, Guillory SB, Sigford B, Cifu DX. Program development and defining characteristics of returning military in a VA Polytrauma Network Site. J Rehabil Res Dev. 2007; 
44(7):1027-34. [PMID: 18075959]

DOI:10.1682/JRRD.2007.05.0073

9. Lew HL, Vanderploeg RD, Moore DF, Schwab K, Friedman L, Yesavage J, Keane TM, Warden DL, Sigford BJ. Overlap of mild TBI and mental health conditions in returning OIF/ OEF service members and veterans. J Rehabil Res Dev. 2007;45(3):xi-xvi. [PMID: 18629743]

10. McLean SA, Kirsch NL, Tan-Schriner CU, Sen A, Frederiksen S, Harris RE, Maixner W, Maio RF. Health status, not head injury, predicts concussion symptoms after minor injury. Am J Emerg Med. 2009;27(2):182-90.

[PMID: 19371526]

DOI:10.1016/j.ajem.2008.01.054

11. Fox DD, Lees-Haley PR, Earnest K, Dolezal-Wood S. Base rates of postconcussive symptoms in health maintenance organization patients and controls. Neuropsychol. 1995; 9(4):606-11. DOI:10.1037/0894-4105.9.4.606

12. Guskiewicz KM, McCrea M, Marshall SW, Cantu RC, Randolph C, Barr W, Onate JA, Kelly JP. Cumulative effects associated with recurrent concussion in collegiate football players: The NCAA Concussion Study. JAMA. 2003;290(19):2549-55. [PMID: 14625331]

DOI:10.1001/jama.290.19.2549

13. Iverson GL, Zasler ND, Lange RT. Post-concussive disorder. In: Zasler ND, Katz DI, Zafonte RD, editors. Brain injury medicine principles and practice. New York (NY): Demos; 2006. p. 373-405.

14. Lees-Haley PR, Fox DD, Courtney JC. A comparison of complaints by mild brain injury claimants and other claimants describing subjective experiences immediately following their injury. Arch Clin Neuropsychol. 2001;16(7):689-95. [PMID: 14589787]

15. American Psychiatric Association. Diagnostic and statistical manual of mental disorders: DSM-IV. 4th ed. Washington (DC): American Psychiatric Association; 1994.

16. Vasterling JJ, Brailey K. Neuropsychological findings in adults with PTSD. In: Vasterling JJ, Brewin CR, editors. Neuropsychology of PTSD: Biological, cognitive, and clinical perspectives. New York (NY): Guilford Press; 2005. p. 178-207.

17. Vasterling JJ, Brailey K, Constans JI, Sutker PB. Attention and memory dysfunction in posttraumatic stress disorder. Neuropsychology. 1998;12(1):125-33. [PMID: 9460740] DOI:10.1037/0894-4105.12.1.125

18. Schwartz CE, Kozora E, Zeng Q. Towards patient collaboration in cognitive assessment: Specificity, sensitivity, and incremental validity of self-report. Ann Behav Med. 1996;18(3):177-84. DOI:10.1007/BF02883395

19. Branca B, Giordani B, Lutz T, Saper JR. Self-report of cognition and objective test performance in posttraumatic headache. Headache. 1996;36(5):300-6. [PMID: 8682671] DOI:10.1046/j.1526-4610.1996.3605300.x
20. Moore LH, Van Gorp WG, Hinken CH, Stern MJ, Swales T, Satz P. Subjective complaints versus actual cognitive deficits in predominantly symptomatic HIV-1 seropositive individuals. J Neuropsychiatry Clin Neurosci. 1997;9(1): 37-44. [PMID: 9017527]

21. Burdick KE, Endick CJ, Goldberg JF. Assessing cognitive deficits in bipolar disorder: Are self-reports valid? Psychiatry Res. 2005;136(1):43-50. [PMID: 16024090]

DOI:10.1016/j.psychres.2004.12.009

22. Allen CC, Ruff RM. Self-rating versus neuropsychological performance of moderate versus severe head-injured patients. Brain Inj. 1990;4(1):7-17. [PMID: 2297602] DOI:10.3109/02699059009026143

23. Gagnon M, Dartigues JF, Mazaux JM, Dequae L, Letenneur L, Giroire JM, Barberger-Gateaup P. Self-reported memory complaints and memory performance in elderly French community residents: Results of the PAQUID research program. Neuroepidemiology. 1994;13(4):145-54.

[PMID: 8090256]

DOI:10.1159/000110373

24. Gass CS, Apple C. Cognitive complaints in closed-head injury: Relationship to memory test performance and emotional disturbance. J Clin Exp Neuropsychol. 1997;19(2): 290-99. [PMID: 9240487] DOI:10.1080/01688639708403858

25. Zigmond AS, Snaith RP. The Hospital Anxiety and Depression Scale. Acta Psychiatr Scand. 1983;67(6):361-70. [PMID: 6880820] DOI:10.1111/j.1600-0447.1983.tb09716.x

26. Weathers FW, Litz BT, Herman DS, Huska JA, Keane TM. The PTSD Checklist (PCL): Reliability, validity, and diagnostic utility. Annual Meeting of the International Society for Traumatic Stress Studies; 1993 Oct; San Antonio, TX.

27. Strauss E, Sherman EM, Spreen O. A compendium of neuropsychological tests: Administration, norms, and commentary. 3rd ed. New York (NY): Oxford University Press; 2006.

28. Randolph C. Repeatable Battery for the Assessment of Neuropsychological Status manual. San Antonio (TX): The Psychological Corporation; 1998.

29. Meyers JE, Meyers KR. Rey Complex Figure Test and Recognition Trial: Professional manual. Lutz (FL): Psychological Assessment Resources; 1995.

30. Wechsler D. WAIS-IV: Administration and scoring manual. New York (NY): The Psychological Corporation; 2008.

31. Zachary RA. Shipley Institute of Living Scale: Revised manual. Los Angeles (CA): Western Psychological Services; 2000.

32. Savage CR, Baer L, Keuthen NJ, Brown HD, Rauch SL, Jenike MA. Organizational strategies mediate nonverbal memory impairment in obsessive-compulsive disorder. Biol Psychiatry. 1999;45(7):905-16. [PMID: 10202579] DOI:10.1016/S0006-3223(98)00278-9 
33. Deckersbach T, Savage CR, Henin A, Mataix-Cols D, Otto MW, Wilhelm S, Rauch SL, Baer L, Jenike MA. Reliability and validity of a scoring system for measuring organizational approach in the Complex Figure Test. J Clin Exp Neuropsychol. 2000;22(5):640-48. [PMID: 11094399] DOI:10.1076/1380-3395(200010)22:5;1-9;FT640

34. Savage CR, Deckersbach T, Wilhelm S, Rauch SL, Baer L, Reid T, Jenike MA. Strategic processing and episodic memory impairment in obsessive compulsive disorder. Neuropsychology. 2000;14(1):141-51. [PMID: 10674806] DOI:10.1037/0894-4105.14.1.141

35. Chamelian L, Feinstein A. The effect of major depression on subjective and objective cognitive deficits in mild to moderate traumatic brain injury. J Neurospychiatry Clin Neurosci. 2006;18(1):33-38. [PMID: 16525068] DOI:10.1176/appi.neuropsych.18.1.33

36. Gunstad J, Suhr JA. "Expectation as etiology” versus "the good old days": Postconcussion syndrome symptom reporting in athletes, headache sufferers, and depressed individuals. J Int Neuropsychol Soc. 2001;7(3):323-33.

[PMID: 11311033] DOI:10.1017/S1355617701733061

37. Iverson GL, Lange RT. Examination of "postconcussionlike” symptoms in a healthy sample. Appl Neuropsychol. 2003;10(3):137-44. [PMID: 12890639] DOI:10.1207/S15324826AN1003_02

38. Julian L, Merluzzi NM, Mohr DC. The relationship among depression, subjective cognitive impairment, and neuropsychological performance in multiple sclerosis. Mult
Scler. 2007;13(1):81-86. [PMID: 17294615]

DOI:10.1177/1352458506070255

39. Sullivan MJ, D’Eon JL. Relation between catastrophizing and depression in chronic pain patients. J Abnorm Psychol. 1990;99(3):260-63. [PMID: 2145334$]$

DOI:10.1037/0021-843X.99.3.260

40. Southwick SM, Yehuda R, Giller EL Jr. Characterization of depression in war-related posttraumatic stress disorder. Am J Psychiatry. 1991;148(2):179-83. [PMID: 1987814]

41. Arnstein P, Caudill M, Mandle CL, Norris A, Beasley R. Self efficacy as the mediator of the relationship between pain intensity, disability and depression in chronic pain patients. Pain. 1999;80(3):483-91. [PMID: 10342410]

42. Comunian AL. Some characteristics of relations among depression, anxiety, and self-efficacy. Percep Mot Skills. 1989;69(3 Pt 1):755-64. [PMID: 2608390]

Submitted for publication November 7, 2009. Accepted in revised form April 15, 2010.

This article and any supplementary material should be cited as follows:

Spencer RJ, Drag LL, Walker SJ, Bieliauskas LA. Selfreported cognitive symptoms following mild traumatic brain injury are poorly associated with neuropsychological performance in OIF/OEF veterans. J Rehabil Res Dev. 2010;47(6):521-30.

DOI:10.1682/JRRD.2009.11.0181 